\title{
Factors influencing quality of life in patients during radiotherapy for head and neck cancer
}

\author{
Małgorzata Żmijewska-Tomczak ${ }^{1}$, Piotr Milecki ${ }^{1,2}$, Karolina Olek-Hrab ${ }^{3}$, Katarzyna Hojan ${ }^{4}$, \\ Wojciech Golusiński ${ }^{5}$, Anna Rucińska ${ }^{1}$, Anna Adamska ${ }^{1}$
}

1Department of Radiotherapy, Greater Poland Cancer Center, Poznan, Poland 2Department of Electroradiology, Poznan University of Medical Sciences, Poznan, Poland ${ }^{3}$ Department of Dermatology, Poznan University of Medical Sciences, Poznan, Poland ${ }^{4}$ Department of Rehabilitation, Greater Poland Cancer Center, Poznan, Poland ${ }^{5}$ Department of Head and Neck Surgery, Greater Poland Cancer Center, Poznan, Poland

Submitted: 6 July 2012

Accepted: 2 November 2012

Arch Med Sci 2014; 10, 6: 1153-1159

DOI: 10.5114/aoms.2013.34317

Copyright @ 2014 Termedia \& Banach

\section{Abstract}

Introduction: Radiotherapy (RT) in combination with chemotherapy is a standard of care for patients with head and neck squamous cell carcinoma (HNSCC). The RT is associated with side effects, which impact on quality of life (QoL). Thus, the aim of this prospective longitudinal study was to investigate the impact of RT on the QoL of patients with HNSCC during RT.

Material and methods: From September 2008 to February 2010, 205 patients with locally advanced HNSCC were enrolled. The data pertaining to their QoL were collected using the EORTC QLQ-C30 and the EORTC Head and Neck Module (QLQ-H\&N35) and then all items were transformed to a 0-100 scale according to the guidelines of the EORTC. The following clinical factors were chosen to study their potential influence on the QoL; site of primary, clinical stage, and methods of therapy: RT vs. chemoradiotherapy (CRT). Additionally, the sociodemographic factors (age, gender, education, habit of smoking) were studied.

Results: Deterioration of almost all scales and items in the QLQ-C3O and QLQ-H\&N35 questionnaire were noted at the end of RT. The following factors negatively influenced the QoL: age $<60$ years $(p<0.05)$, female gender ( $p<0.05)$, habit of smoking ( $p<0.01)$, advanced clinical stage (III and IV) $(p<0.05)$, site of primary (larynx, hypopharynx) $(p<0.01)$, and CRT $(p<0.01)$. Conclusions: Our study showed that RT significantly negatively influenced QoL at the end of the RT course. Additionally, this study demonstrated that age, gender, smoking habit, tumor site, and clinical stage of disease showed a significant effect on the QoL of HNSCC patients during RT.

Key words: head and neck cancer, radiotherapy, quality of life.

\section{Introduction}

Radiotherapy (RT) in patients with head and neck squamous cell carcinoma (HNSCC) causes side effects, which have a negative impact on the quality of life (QoL). The well-known side effects of RT are taste alterations, eating problems (chewing and swallowing), xerostomia, dysphagia, trismus, hoarse voice, bone necrosis, fibrosis of soft tissue, and hearing and speech impairment [1-7]. However, QoL describes the changes that the

\section{Corresponding author:}

Prof. Piotr Milecki MD, PhD

Department of Radiotherapy Greater Poland Cancer Center

15 Garbary St

61-866 Poznan, Poland

Phone +48 618850878

E-mail: piotr.milecki@wco.pl 
disease causes in the patient's life along with the side effects of the treatment in a much broader way than standard classifications of side effects of treatment. Another vital characteristic of QoL is the fact that by definition it is a subjective evaluation and can be assessed from the patient's perspective only. The QoL changes can be considerably dependent on the treatment type and the patient's adaptation to certain situations [8-13]. The most validated QoL tool in oncology is the European Organization for Research of Life Questionnaire Core 30 Items (EORTC QLQ-C30) including the H\&N-35 module [14-19].

The effectiveness of cancer treatment is defined by the overall survival and/or the time of living free of the disease. More frequent use of the combined treatment and the possibility of alternative ways of treatment, especially in the case of head and neck

Table I. Characteristics of patients according to selected clinical factors which can influence the QoL of patients with HNSCC at the end of RT

\begin{tabular}{|c|c|c|}
\hline Variables & $\begin{array}{l}\text { Number } \\
\text { of patients } \\
\quad=205\end{array}$ & Percentage \\
\hline \multicolumn{3}{|l|}{ Tumor site: } \\
\hline Oral cavity and oropharynx & 93 & 45 \\
\hline Larynx and hypopharynx & 112 & 55 \\
\hline \multicolumn{3}{|l|}{ Clinical stage: } \\
\hline$I+I I$ & 17 & 8 \\
\hline III + IV & 188 & 92 \\
\hline \multicolumn{3}{|l|}{ Treatment: } \\
\hline RT & 119 & 58 \\
\hline $\mathrm{CRT}$ & 86 & 42 \\
\hline Sociodemographic factors & $\begin{array}{l}\text { Number } \\
\text { of patients } \\
\quad=205\end{array}$ & Percentage \\
\hline \multicolumn{3}{|l|}{ Age [years]: } \\
\hline$<60$ & 127 & 62 \\
\hline$>60$ & 78 & 38 \\
\hline \multicolumn{3}{|l|}{ Gender: } \\
\hline Male & 163 & 80 \\
\hline Female & 42 & 20 \\
\hline \multicolumn{3}{|l|}{ Education: } \\
\hline Primary & 147 & 71 \\
\hline Secondary & 44 & 21 \\
\hline Higher education & 14 & 8 \\
\hline \multicolumn{3}{|l|}{ Smoking (pack years¹): } \\
\hline More than 30 & 131 & 64 \\
\hline Fewer than 30 & 56 & 27 \\
\hline Never & 18 & 9 \\
\hline
\end{tabular}

${ }_{1}^{1}$ pack years were calculated by multiplying the number of packets smoked per day by the number of years of smoking. cancer, have necessitated more attention to the patients' feelings, their expectations, and the subjective perception of the treatment's effects. Thus, the choice of a method of treatment is a difficult and complex task for both a multidisciplinary team and patients themselves. The evaluation of QoL is helpful in this case since it supplies more information. This facilitates better understanding of the possible physical, psychological, social and functional impact of various treatment methods.

With regard to the above, the study compared the changes of the QoL in the course of RT in patients with head and neck cancer. Furthermore, the influence of selected clinical and socio-demographic factors on the QoL was assessed too.

\section{Material and methods}

\section{Material}

A prospective clinical study was carried out in a group of 205 subjects with HNSCC. The patients had received RT or chemoradiotherapy (CRT). The study was approved by the Bioethical Board of the Medical University of Poznan (Decision no. 1014/07 of 8.11.2007). The recruitment of the subjects began in September 2008 and ended in February 2010. All patients who participated in the study signed an informed consent form. The following inclusion criteria were taken into consideration: no distant metastases, performance status ECOG (0-1), three dimensional conformal RT (3D CRT) or intensitymodulated RT (IMRT), where the prescribed dose fraction was $2 \mathrm{~Gy}$ with a total dose of $70 \mathrm{~Gy}$. The criteria included histopathological confirmation of squamous cell carcinoma of head and neck cancer (HNSCC) with one of the following subsites: oropharynx, hypopharynx, larynx, oral cavity. Patients who did not fulfill the inclusion criteria were not considered for the study. Clinical factors such as the tumor location, clinical stage, method of therapy (RT, CRT), and sociodemographic factors (age, gender, education, smoking habit) were also analyzed. The patients' characteristics are presented in Table I.

The standardized EORTC-QLQ-C30 (version 3.0) questionnaire and QLQ-H\&N35 module were used for the evaluation of QoL. The QLQ-C30 questionnaire is used for general health assessment as well as physical, emotional and social assessment. It contains 30 questions grouped into 5 functional scales: physical functioning (5 questions), functioning in practical roles (2 questions), emotional functioning (4 questions), cognitive functioning (2 questions) and social functioning (2 questions). The questionnaire also includes 3 symptomatic scales - fatigue (3 questions), nausea (2 questions) and pain (2 questions) - as well as 6 single questions evaluating the intensity of the following symptoms: 
dyspnea, sleeplessness, lack of appetite, constipation, diarrhea and financial problems. The last two questions deal with the overall health assessment.

There is a four-degree scale in the answers to the questions in the questionnaire (never 1 , sometimes 2 , often 3 , very often 4 ). The patients completed the questionnaires by themselves and in case of some difficulties in understanding the questions, they asked their doctor or their families for help.

The QLQ-H\&N35 questionnaire evaluates specific symptoms connected with tumors of the head and neck, and their treatment. It has 35 questions grouped into 7 scales: pain (4 questions), swallowing (5 questions), senses (2 questions), speaking (3 questions), eating in the company of others (4 questions), social contacts (4 questions), sexuality (2 questions), and 11 individual questions concerning teeth problems, difficulties with opening the mouth, oral cavity dryness, the presence of thick saliva, coughing, illness awareness, taking pain killers, using food supplements, and losing or gaining weight. Similarly to the core questionnaire, a patient gave one answer to each question, and the answers had a four-degree scale.

\section{Statistical analysis}

EORTC QLQ-C30 and QLQ-H\&N35 questionnaires were drawn up statistically according to the ESTRO guidelines. For each patient the raw coefficient was calculated and then, according to the guidelines, linear transformation was done, which generated a score ranging between 0 and 100 for all the scales and individual symptoms. In the case of the QLQC30 questionnaire a higher coefficient for the functional scales corresponds to a better level of functioning, and a higher level of general health condition means a better QoL. A higher score for the individual symptoms in turn corresponds to greater escalation of the symptom - the patient feels worse. For all the symptoms and scales in the QLQ-H\&N35 questionnaire, a higher score means greater escalation of the problem - worse QoL. For the assessment of QoL before and after RT, the statistical calculations for the dependent trials were made with Student's $t$-test with the linear data distribution. With the aim of assessment of the influence of the analyzed clinical and socio-demographic factors, Student's $t$-test for independent variables was used. For the ultimate check of the chosen method of analysis of the results, the general linear model for repeated measurements was used, which takes into account both the changes between the measurements and the influence of other factors. The statistical analysis was made at the Department of Methods and Techniques of Sociological Research of Adam Mickiewicz University in Poznan. All the calculations were made with SPSS 17.0.

\section{Results}

All patients ( $n=205)$ completed the core questionnaires EORTC QLQ-C30 and QLQ-H\&N35 before and at the end of RT. In the EORTC QLQ-C30 questionnaire, a higher score for the functional scales denotes a better level of functioning and a higher level of the general health condition means a better QoL. A point difference of 10 or more on a scale from 0 to 100 was regarded as a clinically significant score improving or worsening the QoL. This is a common cut-off value used in studies of QoL. It was introduced in accordance with the recommendations suggested by King and Osoba et al. $[19,20]$. A difference of 20 points indicates a parameter of great significance and a 5-point difference only marks its clinical importance. Smoking worsened the QoL of patients at the end of RT in terms of performing life roles, problems with teeth and diarrhea compared to patients who never smoked. Clinical stage differentiated QoL of patients at the end of RT. Worse QoL in terms of physical functioning and damage to the senses of taste and smell was reported by those in stages III and IV of the disease. Localization of the tumor at the end of RT differentiated QoL in just two parameters. Speech disorders occurring in the case of the tumor's location in the larynx and hypopharynx considerably decreased the QoL in these patients. However, difficulties in mouth opening negatively affected the QoL of these patients who had the tumor located in the oral cavity (Tables II and III).

Statistically significant differences in the comparison of the treatments were produced within the QoL parameters such as functioning in life roles, constipation, and weight loss. The patients treated with postoperative CRT reported the greatest decrease in body weight which negatively affected their QoL (Table IV).

The other factors, that is, the average dose in the parotid salivary glands, place of residence, professional activity, marital status, and alcohol consumption, did not significantly affect the QoL assessment at the end of RT.

\section{Discussion}

The results of our study showed that RT significantly negatively influenced the QoL of patients with HNSCC at the end of the RT course in relation to baseline parameters. In the questionnaire QLQ-C30 RT worsened QoL in 11 of the 30 analyzed components, and thus had a very significant negative impact on QoL. At the end of RT results in all symptomatic scales, except diarrhea, achieved a maximum value. All the results of the functional scales were the lowest, which means a very bad performance in various spheres of life. Bjordal et al. obtained very similar results based on an analysis of 280 patients [21]. A higher negative impact on 
Table II. Assessment of QoL and its changes (before vs. at the end of RT) with EORTC QLQ-C30 questionnaire in 205 patients with HNSCC treated with RT

\begin{tabular}{|c|c|c|c|c|c|c|}
\hline \multicolumn{2}{|c|}{ Variables } & \multirow{2}{*}{$\begin{array}{l}\text { Mean } \\
60.20\end{array}$} & \multirow{2}{*}{$\begin{array}{c}\begin{array}{c}\text { Statistical } \\
\text { value } t\end{array} \\
4.556\end{array}$} & \multirow{2}{*}{$\begin{array}{c}\begin{array}{c}\text { Standard } \\
\text { deviation }\end{array} \\
21.750\end{array}$} & \multirow{2}{*}{$\begin{array}{c}\begin{array}{c}\text { Difference } \\
\text { between means }\end{array} \\
8.49\end{array}$} & \multirow{2}{*}{$\begin{array}{c}\text { Value of } p \\
<0.01\end{array}$} \\
\hline p 1 & General condition (before RT) & & & & & \\
\hline & General condition (at the end of RT) & 51.70 & & 22.743 & & \\
\hline \multirow[t]{2}{*}{ p 2} & Physical performance (before RT) & 80.95 & 4.632 & 14.876 & 5.85 & $<0.01$ \\
\hline & Physical performance (at the end of RT) & 75.10 & & 18.288 & & \\
\hline \multirow[t]{2}{*}{ p 3} & Life roles fulfillment (before RT) & 82.68 & 4.143 & 19.091 & 8.45 & $<0.01$ \\
\hline & Life roles fulfillment (at the end of RT) & 74.23 & & 27.036 & & \\
\hline \multirow[t]{2}{*}{ p 5} & Cognitive functioning (the beginning of RT) & 82.93 & 3.031 & 18.035 & 4.39 & $<0.01$ \\
\hline & Cognitive functioning (at the end of RT) & 78.54 & & 23.454 & & \\
\hline \multirow[t]{2}{*}{ p 6} & Social functioning (before RT) & 80.89 & 4.235 & 23.326 & 8.69 & $<0.01$ \\
\hline & Social functioning (at the end of RT) & 72.20 & & 29.322 & & \\
\hline \multirow[t]{2}{*}{ p 7} & Fatigue (before RT) & 31.92 & -8.189 & 22.287 & -15.28 & $<0.01$ \\
\hline & Fatigue (at the end of RT) & 47.21 & & 27.065 & & \\
\hline \multirow[t]{2}{*}{ p 8} & Nausea and vomiting (before RT) & 7.97 & -9.660 & 14.721 & -18.61 & $<0.01$ \\
\hline & Nausea and vomiting (at the end of RT) & 26.59 & & 27.000 & & \\
\hline \multirow[t]{2}{*}{ p 9} & Pain (before RT) & 24.88 & -7.494 & 23.835 & -16.34 & $<0.01$ \\
\hline & Pain (at the end of RT) & 41.22 & & 30.048 & & \\
\hline \multirow[t]{2}{*}{ p 11} & Insomnia (before RT) & 34.80 & -2.185 & 30.379 & -4.90 & $<0.05$ \\
\hline & Insomnia (at the end of RT) & 39.71 & & 32.380 & & \\
\hline p 12 & Appetite loss (before RT) & 20.49 & -13.704 & 27.072 & -39.35 & $<0.01$ \\
\hline
\end{tabular}

the QoL according to these authors occurred in the first and second month from the beginning of RT.

In our study group, the greatest negative changes were noted in relation to the loss of appetite $(\Delta=39)$. Loss of taste and the increasing difficulty in swallowing, first solid food and then fragmented and fluid, and increasing pain in the mouth and throat, caused the patients to lose their appetite and consequently to give up eating.

The next four components that significantly influenced the deterioration of QoL in patients is the occurrence of nausea and vomiting $(\Delta=18)$, constipation $(\Delta=17)$, pain $(\Delta=16)$ and fatigue $(\Delta=15)$. Nausea and vomiting were caused most frequently by the emetogenic effect of cisplatin in the patients treated with CRT. The RT was the cause of pain but the high value of $\Delta$ indicates the need for more intensive treatment of pain in patients during RT. The severity of pain was associated with tumor location and the method of RT. The largest increase of pain between the beginning and the end of RT was reported during CRT in the larynx and hypopharynx. In patients who had received CRT, the pain rose in a similar manner.

Fatigue reported by patients at the end of RT achieved a clinically important value $(\Delta=15)$, confirming that this is a symptom that greatly worsens QoL. Women experienced greater fatigue than men. Our study showed that patients treated with IMRT technique report fatigue more frequently compared to those treated with 3D CRT technique. The most probable cause of such results is that a low dose is used on a large volume of the brain when using IMRT technique [22]. In the study by Bjordal et al., the fatigue reported by the patients reached the maximum value shortly after the beginning of RT, which was also observed in our study [21]. Fang et al. assessed the changes in QoL before and at the end of the course of RT in 102 patients with advanced HNSCC using the Chinese version of the questionnaires EORTC QLQ-C30 and QLQ-H\&N35 [23]. The authors found that the level of fatigue before the treatment was significantly correlated with survival in the patients treated with RT for advanced HNSCC.

In our analysis the parameters such as social functioning $(\Delta=9)$, general health $(\Delta=8)$, functioning in life roles $(\Delta=8)$, and physical functioning $(\Delta=6)$ reached statistical significance. It is natural that during RT lasting about 2 months the patient who is hospitalized does not work or do any housework. His social activity virtually disappears and the physical condition weakens considerably.

In our study in the questionnaire QLQ-H\&N35 all the parameters reached maximum values, and 12 of them were clinically significant $(\Delta \geq 10)$. The 
Table III. Assessment of QoL (before vs. at the end of RT) with EORTC QLQ-H\&N35 questionnaire in 205 patients with HNSCC treated with RT

\begin{tabular}{|c|c|c|c|c|c|c|}
\hline \multicolumn{2}{|c|}{ Variables } & \multirow{2}{*}{$\begin{array}{l}\text { Mean } \\
21.85\end{array}$} & \multirow{2}{*}{$\begin{array}{c}\text { Statistical } \\
\text { value } t\end{array}$} & \multirow{2}{*}{$\begin{array}{c}\text { Standard } \\
\text { deviation }\end{array}$} & \multirow{2}{*}{$\begin{array}{c}\text { Difference } \\
\text { between means }\end{array}$} & \multirow{2}{*}{$\begin{array}{c}\text { Value of } p \\
<0.01\end{array}$} \\
\hline p 1 & Pain (before RT) & & & & & \\
\hline & Pain (the end of RT) & 51.59 & & 26.076 & & \\
\hline \multirow[t]{2}{*}{ p 2} & Swallowing (before RT) & 20.53 & \multirow[t]{2}{*}{-12.137} & 23.764 & \multirow[t]{2}{*}{-28.17} & \multirow[t]{2}{*}{$<0.01$} \\
\hline & Swallowing (the end of RT) & 48.70 & & 28.302 & & \\
\hline \multirow[t]{2}{*}{ p 3} & Senses (before RT) & 22.60 & \multirow[t]{2}{*}{-17.031} & 28.891 & \multirow[t]{2}{*}{-41.05} & \multirow[t]{2}{*}{$<0.01$} \\
\hline & Senses (the end of RT) & 63.66 & & 31.664 & & \\
\hline \multirow[t]{2}{*}{ p 4} & Speech (before RT) & 34.58 & \multirow[t]{2}{*}{-3.166} & 25.405 & \multirow[t]{2}{*}{-6.55} & \multirow[t]{2}{*}{$<0.01$} \\
\hline & Speech (the end of RT) & 41.14 & & 25.953 & & \\
\hline \multirow[t]{2}{*}{ p 5} & $\begin{array}{l}\text { Difficulties with eating in company } \\
\text { (before RT) }\end{array}$ & 19.55 & \multirow[t]{2}{*}{-10.410} & 23.414 & \multirow[t]{2}{*}{-20.97} & \multirow[t]{2}{*}{$<0.01$} \\
\hline & $\begin{array}{l}\text { Difficulties with eating in company } \\
\text { (the end of RT) }\end{array}$ & 40.53 & & 27.180 & & \\
\hline \multirow[t]{2}{*}{ p 6} & Difficulties with social contacts (before RT) & 18.63 & \multirow[t]{2}{*}{-4.702} & 22.710 & \multirow[t]{2}{*}{-8.19} & \multirow[t]{2}{*}{$<0.01$} \\
\hline & $\begin{array}{l}\text { Difficulties with social contacts } \\
\text { (the end of RT) }\end{array}$ & 26.83 & & 23.482 & & \\
\hline \multirow[t]{2}{*}{ p 7} & Sexuality (before RT) & 35.69 & \multirow[t]{2}{*}{-3.374} & 32.900 & \multirow[t]{2}{*}{-9.43} & \multirow[t]{2}{*}{$<0.05$} \\
\hline & Sexuality (the end of RT) & 45.12 & & 35.248 & & \\
\hline p 9 & Mouth opening (before RT) & 22.93 & -7.589 & 32.508 & -18.04 & $<0.01$ \\
\hline & Mouth opening (the end of RT) & 40.98 & & 36.173 & & \\
\hline p 10 & Oral cavity dryness (before RT) & 26.99 & -12.245 & 28.159 & -33.98 & $<0.01$ \\
\hline & Oral cavity dryness (the end of RT) & 60.98 & & 33.090 & & \\
\hline p 11 & Thick saliva (before RT) & 29.92 & -12.654 & 29.783 & -34.79 & $<0.01$ \\
\hline & Thick saliva (the end of RT) & 64.72 & & 32.111 & & \\
\hline p 13 & Illness realization (before RT) & 27.32 & -6.589 & 28.804 & -16.26 & $<0.01$ \\
\hline & Illness realization (the end of RT) & 43.58 & & 32.477 & & \\
\hline p 14 & Pain killers (before RT) & 48.77 & 7.841 & 50.108 & 29.55 & $<0.01$ \\
\hline & Pain killers (the end of RT) & 19.21 & & 39.494 & & \\
\hline p 15 & Food supplements (before RT) & 74.02 & 4.062 & 43.961 & 16.17 & $<0.01$ \\
\hline & Food supplements (the end of RT) & 57.84 & & 49.502 & & \\
\hline p 17 & Body weight decrease (before RT) & 60.00 & 9.536 & 49.110 & 40.48 & $<0.01$ \\
\hline & Body weight decrease (the end of RT) & 19.51 & & 39.726 & & \\
\hline p 18 & Body weight increase (before RT) & 65.85 & -4.958 & 47.536 & -19.02 & $<0.05$ \\
\hline & Body weight increase (the end of RT) & 84.88 & & 35.914 & & \\
\hline
\end{tabular}

analysis of the impact of clinical and sociodemographic factors on QoL showed that the damage of the sense of taste and smell at the end of RT was reported by statistically significantly more patients in clinical stages III and IV and patients above 60 years of age.

A decrease in body weight $(\Delta=40)$ in our study statistically significantly worsened the HRQOL (Health-Related Quality of Life) of the patients treated with CRT. The relationship between HRQOL and weight loss was studied by Petruson et al. [24]. The analysis in the group of 49 patients showed that the patients who at baseline, before the treatment, reported a decrease in body weight above $10 \%$, after the treatment experienced a significantly lower QoL than those who lost less weight.

Pain in the mouth and throat at the end of RT reached a high value of $\Delta=30$. Similar results were obtained in the group of 149 patients with carcinoma of the oropharynx and oral cavity [25].

In the study conducted by Hammerlid et al. evaluating the QoL before RT, younger age were asso- 
Table IV. The influence of clinical and sociodemographic factors on QoL in 205 patients with HNSCC treated with RT

\begin{tabular}{|c|c|c|c|}
\hline Variables & Mean & Standard deviation & Value of $p$ \\
\hline \multicolumn{4}{|c|}{ Pain } \\
\hline \multicolumn{4}{|l|}{ Gender: } \\
\hline Female & 60.52 & 24.971 & \multirow[t]{2}{*}{$<0.05$} \\
\hline Male & 49.23 & 25.857 & \\
\hline \multicolumn{4}{|c|}{ Senses } \\
\hline \multicolumn{4}{|l|}{ Age [years]: } \\
\hline$<60$ & 59.32 & 31.543 & \multirow[t]{2}{*}{$<0.05$} \\
\hline$>60$ & 70.73 & 30.765 & \\
\hline \multicolumn{4}{|c|}{ Social functioning } \\
\hline \multicolumn{4}{|l|}{ Education: } \\
\hline Primary & 75.74 & 28.284 & \multirow[t]{2}{*}{$<0.05$} \\
\hline Secondary and higher & 63.22 & 30.229 & \\
\hline \multicolumn{4}{|c|}{ Life roles fulfillment } \\
\hline \multicolumn{4}{|l|}{ Smoking: } \\
\hline More than 30 pack years & 69.35 & 27.112 & \multirow[t]{2}{*}{$<0.01$} \\
\hline Never & 88.89 & 15.125 & \\
\hline \multicolumn{4}{|c|}{ Physical performance } \\
\hline \multicolumn{4}{|l|}{ Clinical stage: } \\
\hline I, II & 84.71 & 14.096 & \multirow[t]{2}{*}{$<0.05$} \\
\hline III, IV & 74.26 & 18.361 & \\
\hline \multicolumn{4}{|c|}{ Senses } \\
\hline I, II & 46.08 & 37.974 & \multirow[t]{2}{*}{$<0.05$} \\
\hline III, IV & 65.25 & 30.655 & \\
\hline \multicolumn{4}{|c|}{ Speech } \\
\hline \multicolumn{4}{|l|}{ Tumor site: } \\
\hline Larynx and hypopharynx & 45.34 & 24.875 & $<0.05$ \\
\hline Oral cavity & 31.94 & 24.238 & \\
\hline \multicolumn{4}{|c|}{ Mouth opening } \\
\hline Larynx and hypopharynx & 31.25 & 32.042 & $<0.01$ \\
\hline Oral cavity & 44.79 & 37.493 & \\
\hline \multicolumn{4}{|c|}{ Body weight decrease } \\
\hline \multicolumn{4}{|l|}{ Treatment methods: } \\
\hline CRT & 29.63 & 45.875 & $<0.01$ \\
\hline RT & 6.98 & 25.777 & \\
\hline
\end{tabular}

ciated with lower levels of emotional and social functioning [26]. Our study also showed poorer emotional functioning in younger patients. The study by Alicikus et al. in a group of 110 Turkish patients showed a relationship between age and opening of the mouth and dental problems [27]. Age above 60 was a factor positively influencing the QoL of patients in terms of emotional functioning and pain perception and minor dental problems and financial difficulties. Older patients, because of having experienced other diseases, reacted less emotionally and accepted pain discomforts [28].

In conclusion, RT significantly worsened the QoL in patients with HNSCC. It was demonstrated that the tumor localization, clinical stage, method of treatment, gender, age, education and smoking have a statistically significant influence on QoL at the end of the course of RT. The greatest negative impact of RT was observed in terms of damage to 
the sense of taste and smell, weight loss, dry mouth, thick saliva retention, pain, loss of appetite, nausea and vomiting as well as fatigue. The analysis of the selected clinical and sociodemographic factors revealed that the location of the tumor in the larynx and hypopharynx was associated with the greatest negative impact on QoL.

\section{References}

1. Harrison LB, Zelefsky MJ, Pfister DG, et al. Detailed quality of life assessment in patients treated with primary radiotherapy for squamous cell cancer of the base of the tongue. Head Neck 1997; 19: 169-75.

2. Cooper JS, Fu K, Marks J, et al. Late effects of radiation therapy in the head and neck region. Int J Radiat Oncol Biol Phys 1995; 31: 1141-64.

3. Constine LS. What else don't we know about the late effects of radiation in patients treated for head and neck cancer? Int J Radiat Oncol Biol Phys 1995; 41: 427-9.

4. Zielińska-Więczkowska H, Betłakowski J. Quality of life in cancer patients undergoing chemotherapy. Wspolczesna Onkol 2010; 14: 276-80.

5. Epstein JB, Emerton S, Kolbinson DA, et al. Quality of life and oral function following radiotherapy for head and neck cancer. Head Neck 1999; 21: 1-11.

6. Dirix P, Nuyts S, Delaere P, et al. The influence of xerostomia after radiotherapy on quality of life. Supportive Care in Cancer 2007; 2: 171-9.

7. Terhaard $\mathrm{CHJ}$, Lubsen $\mathrm{H}$, Rasch CRN, et al. The role of radiotherapy in the treatment of malignant salivary gland tumors. Int J Radiat Oncol Biol Phys 2005; 61: 103-11.

8. De Graeff A, De Leeuw JR, Ros WJ. A prospective study of quality of life of laryngeal cancer patients treated with radiotherapy. Head Neck 1999; 21: 291-6.

9. List MA, Stracks J. Quality of life and late toxicities in head and neck cancer. In: Brockstein BE, Master GA (ed.). Head and neck cancer. Kluwer Academic Publishers, Norwell, MA 2003.

10. List MA, Mumby P, Haraf D, et al. Performance and quality of life outcomes in patients completing concomitant chemoradiotherapy protocols for head and neck cancer. Qual Life Res 1997; 6: 274-84.

11. Baile WF, Gibertini M, Scott L, et al. Depression and tumor stage in cancer of head and neck. Psychol Oncol 1992; 1: 15-24.

12. Stanczyk MM. Music therapy in supportive cancer care. Rep Pract Oncol Radiother 2011; 16: 170-2.

13. Aaronson NK, Ahmedzai S, Bergman B, et al. The European Organization for Research and Treatment of Cancer QLQ-C30: a quality-of-life instrument for use in international clinical trials in oncology. J Natl Cancer Inst 1993; 85: 365-76.

14. Bjordal K, Kaasa S. Psychometric validation of the EORTC Core Quality of Life Questionnaire, 30-item version and a diagnosis-specific module for head and neck cancer patients. Acta Oncol 1992; 31: 311-21.

15. Cella D. F.A.C.I.T. MANUAL: Manual of the Functional Assessment of Chronic Illness Therapy (FACIT) Scales, Version 4. Chicago, Center on Outcomes, Research and Education, Evanston Hospital Healthcare and Northwestern University 1997.

16. Bjordal K, Hammerlid E, Ahlner-Elmqvist M, et al. Quality of life head and neck cancer patients: validation of the European Organization for Research and Treatment of
Cancer Quality of Life Questionnaire-H\&N35. J Clin Oncol 1999; 17: 1008-19.

17. List MA, D'Antonio LL, Cella DF, et al. The performance status scales for head and neck cancer patients and the functional assessment of cancer therapy-head and neck scale. A study of utility and validity. Cancer 1996; 77 : 2294-301.

18. Bjordal K, de Graff A, Fayers PM, et al. A 12 country field study of the EORTC QLQ-C30 (version 3.0) and the head and neck cancer specific module (EORTC QLQ-H\&N35) in head and neck patients: EORTC Quality of Life Group. Eur J Cancer 2000; 36: 1796-807.

19. King MT. The interpretation of scores from the EORTC quality of life questionnaire QLQ-C30. Qual Life Res 1996; 5: 555-67.

20. Osoba D, Rodrigues G, Myles J, Zee B, Pater J. Interpreting the significance of changes in health-related quality of life scores. J Clin Oncol 1998; 16: 139-44.

21. Bjordal K, Ahlner-Elmqvist M, Hammerlid E, et al. A prospective study of quality of life in head and neck cancer patients. Part II: longitudinal data. Laryngoscope 2001; 111: $1440-52$

22. Nutting C, A'Hern R, Regers MS. First results of a phase III multicentre randomised controlled a trial of intensity modulated (IMRT) vs. conventional radiotherapy (RT) in head and neck cancer (PARSPORT). J Clin Oncol 2009; 27: $18 \mathrm{~S}$.

23. Fang FM, Liu YT, Tang Y, et al. Quality of life as a survival predictor for patients with advanced head nad neck carcinoma treated with radiotherapy. Cancer 2004; 100: 425-32.

24. Petruson KM, Silander EM, Hammerlid EB. Quality of life as predictor of weight loss in patients with head and neck cancer. Head Neck 2005; 27: 302-10.

25. Infante-Cossio P, Torres-Carranza E, Cayuela A, et al. Quality of life in patients with oral and oropharyngeal cancer. Int J Oral Maxillofac 2009; 38: 250-5.

26. Hammerlid E, Bjordal K, Ahler-Elmqvist M. A prospective study of quality of life in head and neck cancer patients. Part I: at diagnosis. Laryngoscope 2001; 111: 669-680.

27. Alicikus ZA, Akman F, Ataman OU, et al. Importance of patient, tumour and treatment related factors on quality of life in head and neck cancer patients after definitive treatment. Eur Arch Otorhinolaryngol 2009; 266: 1461-8.

28. Spych M, Gottwald L, Klonowicz M, et al. Clinical research?The analysis of prognostic factors affecting postradiation acute reaction after conformal radiotherapy for non-small cell lung cancer. Arch Med Sci 2010; 6: 756-63. 